\section{Anaerobic Degradation of Phenolic Compounds}

\author{
B. Schink (更), B. Philipp, J. Müller \\ Fakultät für Biologie, Universität Konstanz, Postfach 5560, \\ D-78457 Constance, Germany \\ e-mail: Bernhard.Schink@uni-konstanz.de \\ Tel.: +49-7531-882140 \\ Fax: + 49-7531-882966
}

Mononuclear aromatic compounds are degraded anaerobically through three main pathways, the benzoyl-CoA pathway, the resorcinol pathway, and the phloroglucinol pathway. Various modification reactions channel a broad variety of mononuclear aromatics including aromatic hydrocarbons into either one of these three pathways. Recently, a further pathway was discovered with hydroxyhydroquinone as central intermediate through which especially nitrate-reducing bacteria degrade phenolic compounds and some hydroxylated benzoates. Comparison of the various strategies taken for the degradation of aromatics in the absence of oxygen demonstrates that the biochemistry of breakdown of these compounds is determined largely by the overall reaction energetics and, more precisely, by the redox potentials of the electron acceptor systems used. Nitrate reducers differ in their strategies significantly from those used by sulfate-reducing or fermenting bacteria.

\section{Introduction}

Aromatic compounds are widespread in nature and fulfill widely varied functions in biochemistry. The structural polymer lignin comprises about $30 \%$ of plant material and is the second most important polymer in nature after cellulose (Adler 1977). Lignin derives its importance in wood and ligninaceous grasses by its structural rigidity, which is due to its three-dimensional organization and provides wood its desired mechanical strength and stability against microbial attack for decades and even centuries. Mono- and oligonuclear aromatic compounds are important constituents of plant tissue, where they act as plant protectants that are either toxic to invading micro-organisms or polymerize upon exposure to air through radical-catalyzed polymerization reactions, to act as a wound seal. Aromatic amino acids add structural elements to the tertiary structure of proteins. In numerous coenzymes aromatic residues increase and define the reactivity of prosthetic groups in specific activation reactions and maintenance of reactive transition states. Quinones and flavins act as electron transfer components in various electron transfer reactions.

Among the approx. 800,000 organic compounds known in 1987, about $30 \%$ were of aromatic nature (Franck and Stadelhofer 1987). Synthetic aromatic compounds being are produced in increasing numbers and are finding wide applications to confined or noncontrolled environments. Despite their often unusual structure only few of these compounds appear to cause environmental problems due to incomplete degradation. Micro-organisms, especially bacteria, are responsible for most of these degradation processes and have developed an impressive adaptative capacity for degrading synthetic compounds, even those which show only little resemblance to preexisting templates among natural com- 
pounds. This phenomenon is even more striking considering that several of these compounds have been produced only for the past 30-50 years but have challenged the evolution of degradative pathways with an broad array of new such pathways.

Due to the ready availability of oxygen in the atmosphere and in most of the biosphere, including plant and animals surfaces, soil and most of our water bodies, the microbial degradation of aromatic compounds is carried out mostly by aerobic bacteria and fungi which can employ molecular oxygen for substrate activation in oxygenase reactions. The great variety of aromatic substances are transformed by (such) mono- and dioxygenases to a few key intermediates by the introduction of hydroxy groups and the removal of certain substituents (channeling reactions). The most prominent intermediates are catechol, protocatechuate, and gentisate, which are subject to ring cleavage in a further oxygenase-dependent step, either between or vicinal to the hydroxy groups of the aromatic ring (Dagley 1971; Schlegel 1992). Thus an unsaturated, open-chain carboxylic acid is formed which undergoes further degradation, typically to an acetyl and a succinyl derivative. Each oxygenase reaction is highly exergonic, releasing about $300 \mathrm{~kJ} / \mathrm{mol}$ reaction (equivalent to 4 or 5 ATP units) as heat, which is the price for the exploitation of a comparably stable group of substrates as energy and carbon source. In all cases of aerobic breakdown of aromatic compounds the primary attack and ring-cleavage step are oxidative reactions of this kind.

\section{Anaerobic Breakdown of Aromatic Compounds}

Anoxic environments develop where organic matter is degraded through microbial activity, and oxygen has only limited access, for example, in sediments of lakes and oceans, in anoxic hypolimnetic water bodies, and inside the digestive tract of higher animals (Schink 1988, 1989). The obvious indispensability of molecular oxygen for aerobic breakdown of aromatics obscured for several decades the possibility of an alternative, oxygen-independent breakdown of these compounds. Although the complete degradation of benzoate, several phenols, and lignin monomers to methane and carbon dioxide under strictly anoxic conditions had been demonstrated as early as the 1930s (Tarvin and Buswell 1934), several textbooks neglected these studies until the 1980s, when the earlier experiments were repeated under strictly controlled conditions (Healy and Young 1978,
1979). Principally during the 1980 s anaerobic breakdown of several mononuclear aromatics was documented in detail, leading to the identification of three key intermediates by which mononuclear aromatic compounds are channeled, i.e., benzoyl-CoA, resorcinol, and phloroglucinol (Evans and Fuchs 1988; Fuchs et al. 1994; Heider and Fuchs 1997; Schink et al. 1992). The common feature of the three pathways is that the aromatic nucleus is destabilized via a reductive rather than an oxidative attack. The benzoyl-CoA pathway appears to be the most important one because a broad variety of compounds enter this path, including phenol, various hydroxybenzoates, phenylacetate, aniline, certain cresols and even the hydrocarbon toluene (Harwood et al. 1999; Heider and Fuchs 1997; Schink et al. 1992). Benzoyl-CoA is formed either through a variety of channeling reactions (e.g., removal of substituents such as hydroxy groups) which are carried out at the CoA-ester level or directly from benzoate and HSCoA in an AMP-releasing ligase reaction. Once benzoyl-CoA is formed, the stability of the aromatic ring structure is overcome by a reductive step, as shown with the nitrate-reducing bacterium Thauera aromatica. Two single electrons and protons are introduced, probably through a radical intermediate, to form cyclohexadiene carboxyl-CoA as first identifiable product (Boll and Fuchs 1995; Koch et al. 1993). Since the reduction in the benzene ring to a cyclohexadiene derivative is an endergonic reaction with its physiological electron donor ferredoxin $\left(E_{0}{ }^{\prime}=-450 \mathrm{mV}\right.$; Boll and Fuchs 1998), it requires the investment of energy in the form of ATP. The present concept is that 2 ATP are hydrolyzed to $\mathrm{ADP}+\mathrm{P}_{\mathrm{i}}$, probably one with each electron introduced (Boll et al. 1997). Thus the benzoyl-CoA pathway as described here involves a rather high energy input for substrate-activation and dearomatization. Nitrate-reducing bacteria can recover this energy investment through the further breakdown of the C7-dicarboxylic acid derivative produced upon ring cleavage, via $\beta$-oxidation to three acetyl-CoA residues which are finally oxidized in the citric acid cycle. There is some evidence that the phototrophic bacterium Rhodopseudomonas palustris reduces benzoyl-CoA further to cyclohexene carboxyl-CoA, either directly or in two subsequent reduction steps (Harwood et al. 1999). Fermenting and sulfate-reducing bacteria can recover only little energy in the further breakdown of the open-chain intermediate and appear to generate a reaction for benzoyl-CoA dearomatization that introduces four electrons and protons into the ring structure, leading directly to the cyclohexene carboxyl derivative (Harwood et al. 1999; Schöcke and Schink 1999). This reduction is 
exergonic with, for example, $\mathrm{NAD}(\mathrm{P}) \mathrm{H}$ electrons and could thus be catalyzed without a net investment of ATP. However, knowledge on the biochemistry of this new reaction is still fragmentary.

Resorcinol and phloroglucinol both carry hydroxy groups in meta position to each other, which allows tautomerization to the enol form. This generates an isolated double bond which can be easily reduced. Further details of these reactions are provided below.

One of the most exciting discoveries in the field was the observation that aromatic hydrocarbons such as benzene, toluene, ethylbenzene, and xylenes (BTEX) can also be completely degraded in the absence of molecular oxygen (Altenschmidt and Fuchs 1991; Beller et al. 1996; Dolfing et al. 1990; Lovley et al. 1995; Rabus and Widdel 1995; Rabus et al. 1993; Schocher et al. 1991; Seyfried et al. 1994). Among the numerous aromatic hydrocarbons tested, toluene was degraded the fastest. It is activated by addition to fumarate, probably through a radical intermediate, to form benzylsuccinate (Beller and Spormann 1997a,b; Biegert et al. 1996; Heider et al. 1999). Benzylsuccinate releases succinyl-CoA through $\beta$-oxidation, leading again to benzoyl-CoA as key intermediate. Degradation of ethylbenzene under nitrate-reducing conditions is initiated by hydroxylation of the alkyl side-chain to 1-phenylethanol which is metabolized further again to benzoylCoA (Ball et al. 1996; Rabus and Heider 1998). Pure cultures are also available degrading $o$ - and $m$-xylene under sulfate- or nitrate reducing conditions (Harms et al. 1999); a sulfate-reducing pure culture degrading naphthalene has recently also been described (Galushko et al. 1999), which opens the field of polycyclic aromatic hydrocarbon degradation to biochemical investigation.

The following overview concentrates on the anaerobic microbial degradation of phenols, some of which appear to enter the benzoyl-CoA pathway while others take different pathways that are independent of CoA-activation. Recent studies have shown that there is even more diversity in anaerobic aromatic degradation than has been previously been thought.

\section{Anaerobic Degradation of Phenol and Monohydroxybenzoates}

Anaerobic degradation of phenol has been studied most intensively with the nitrate-reducing bacterium T. aromatica (Tschech and Fuchs 1989). The reaction can be followed in vitro with phenylphosphate as substrate, which is carboxylated to 4-hydroxybenzoate and then further degraded (see below). This finding, together with the observation of isotope exchange between phenylphosphate and free phenol, indicates that phenylphosphate is really the substrate of the carboxylation reaction; however, the phosphate donor for phenol phosphorylation is still unknown (Lack and Fuchs 1992, 1994). Whether sulfate-reducing or fermenting bacteria cooperating with methanogenic partners use the same pathway for phenol degradation remains still to be examined. An H/D-exchange at the carbon atom 4 of phenol by cell suspensions of a methanogenic phenol-degrading enrichment culture indicates that these cultures also activate phenol through a carboxylation reaction at this position (Gallert et al. 1991). Whether these bacteria also activate phenol for carboxylation by a primary phosphorylation remains unknowns. The overall energy budget of fermentative phenol degradation is very tight and hardly allows a full ATP equivalent or even more to be spent in this carboxylation reaction.

The biochemistry of phenol degradation by sulfatereducing bacteria has not yet been studied, but it is likely to proceed through the same pathway as in fermenting bacteria. 4-Hydroxybenzoate is an intermediate of phenol degradation and various other aromatic compounds. The anaerobic degradation has been well studied with $T$. aromatica and $R$. palustris. Degradation is initiated by CoA-thioesterification forming 4-hydroxybenzoyl-CoA through a ligase reaction (Biegert et al. 1993; Gibson et al. 1994) analogous to benzoyl-CoA formation from benzoate. 4-Hydroxybenzoyl-CoA is subsequently reductively dehydroxylated with ferredoxin as physiological electron donor (Breese and Fuchs 1998) to benzoyl-CoA by 4-hydroxybenzoyl-CoA reductase (Fig. 1). The purified enzyme has been identified as a molybdenum-flavin-iron-sulfur protein and its genes sequenced from both organisms (Brackmann and Fuchs 1993; Breese and Fuchs 1998; Gibson et al. 1997). The hydroxy group of 4-hydroxybenzoylCoA can be removed through a radical mechanism facilitated by the thioester moiety (Buckel and Keese 1995; El Kasmi et al. 1995). Little is known about degradation of 4-hydroxybenzoate by fermenting bacteria. In methanogenic enrichment cultures it is rapidly decarboxylated to phenol, which is slowly degraded further finally to methane and $\mathrm{CO}_{2}$ (Tschech and Schink 1986). Decarboxylation to phenol occurs also in Clostridium hydroxybenzoicum; however, 4-hydroxybenzoate is only cometabolized during fermentation of amino acids and does not serve as a source of carbon or energy (Zhang and Wiegel 1994). Thermodynamically the fermentation 


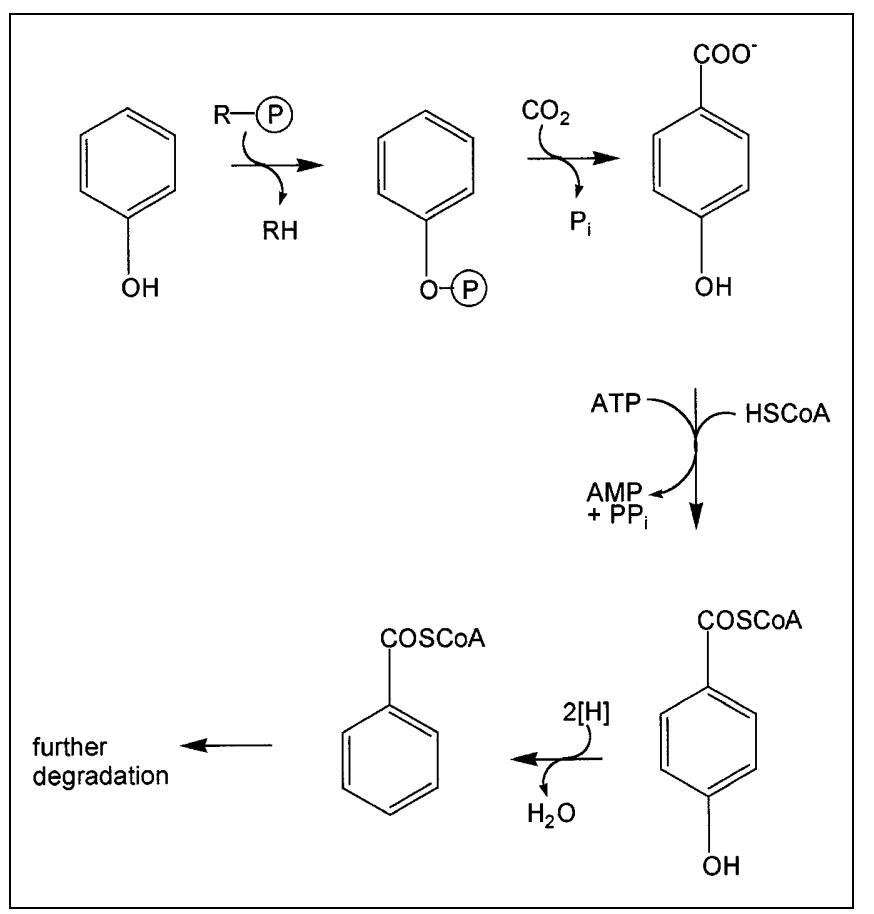

Fig. 1. Initial steps in phenol degradation by the denitrifying bacterium Thauera aromatica. $\mathrm{R}$ represents an yet unknown phosphoryl group donor

of 4-hydroxybenzoate to fatty acids is possible even in pure culture, as illustrated by 3-hydroxybenzoate (Brauman et al. 1998).

3-Hydroxybenzoate is comparably stable and does not decarboxylate spontaneously. It had earlier been hypothesized that the hydroxy group is reductively eliminated to allow further degradation through the benzoyl-CoA pathway (Tschech and Schink 1986), and experimental evidence of this reaction was obtained only recently with the newly isolated Sporotomaculum hydroxybenzoicum (Brauman et al. 1998). Cell-free extracts of this bacterium catalyzed a reductive dehydroxylation of 3-hydroxybenzoylCoA with reduced cob(I)alamine as electron donor (Fig. 2a; Müller and Schink, submitted). As with other cob(I)alamine-catalyzed reactions, the question remains of how reduction to the completely reduced state of this coenzyme is accomplished with an electron supply at a redox potential of $-630 \mathrm{mV}$, far lower than that of any common organic or inorganic electron donor substrate. An entirely different strategy in anaerobic degradation of 3-hydroxybenzoate is used by a nitrate-reducing bacterium, strain BoNHB. This bacterium oxidizes 3-hydroxybenzoate to gentisate (2,5-dihydroxybenzoate), probably followed by further hydroxylation and decarboxylation forming hydroxyhydroquinone (HHQ;
A<smiles>O=C(O)c1cccc(C(=O)OCc2cccc(O)c2)c1</smiles>

B

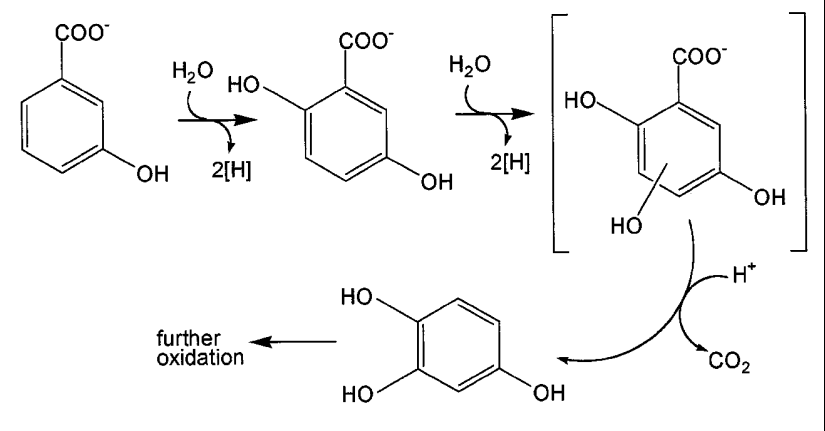

Fig. 2A,B. Initial steps in anaerobic degradation of 3-hydroxybenzoate. A) Degradation via reductive dehydroxylation by Sporotomaculum hydroxybenzoicum. B) Degradation through hydroxylation by the nitrate-reducing strain BoNHB

Fig. 2b; Müller and Schink, in preparation). The further fate of HHQ is discussed below.

The third isomer, 2-hydroxybenzoate (salicylate), appears to be degraded in a similar manner as 4-hydroxybenzoate, involving $\mathrm{CoA}$ esterification and reductive dehydroxylation yielding benzoyl-CoA (Bonting and Fuchs 1996). Nonetheless, direct reduction by benzoyl-CoA reductase to a nonaromatic hydroxy cyclohexadiene derivative may also occur (Bonting and Fuchs 1996).

Cresols (methylphenols) are anaerobically degraded by various pathways depending on the position of the hydroxy group. $p$-Cresol is hydroxylated at the methyl group by an oxygen-independent reaction, probably by a quinomethide intermediate, as suggested earlier for an aerobic Pseudomonas strain (Fig. 3a; Hopper 1978). The redox potential of this oxidation reaction is in the range of $+100 \mathrm{mV}$ (calculated after Thauer et al. 1977) and the reaction is therefore easy for a nitrate-reducing bacterium that couples this oxidation, for example, with the reduction in a $c$-type cytochrome at $+232 \mathrm{mV}$ (Hopper et al. 1991). Sulfate-reducing or fermenting bacteria, on the other hand, have difficulties in disposing of these electrons, and nothing is yet known about the biochemistry of $p$-cresol degradation under such conditions. $o$-Cresol can be carboxylated to 3-me- 


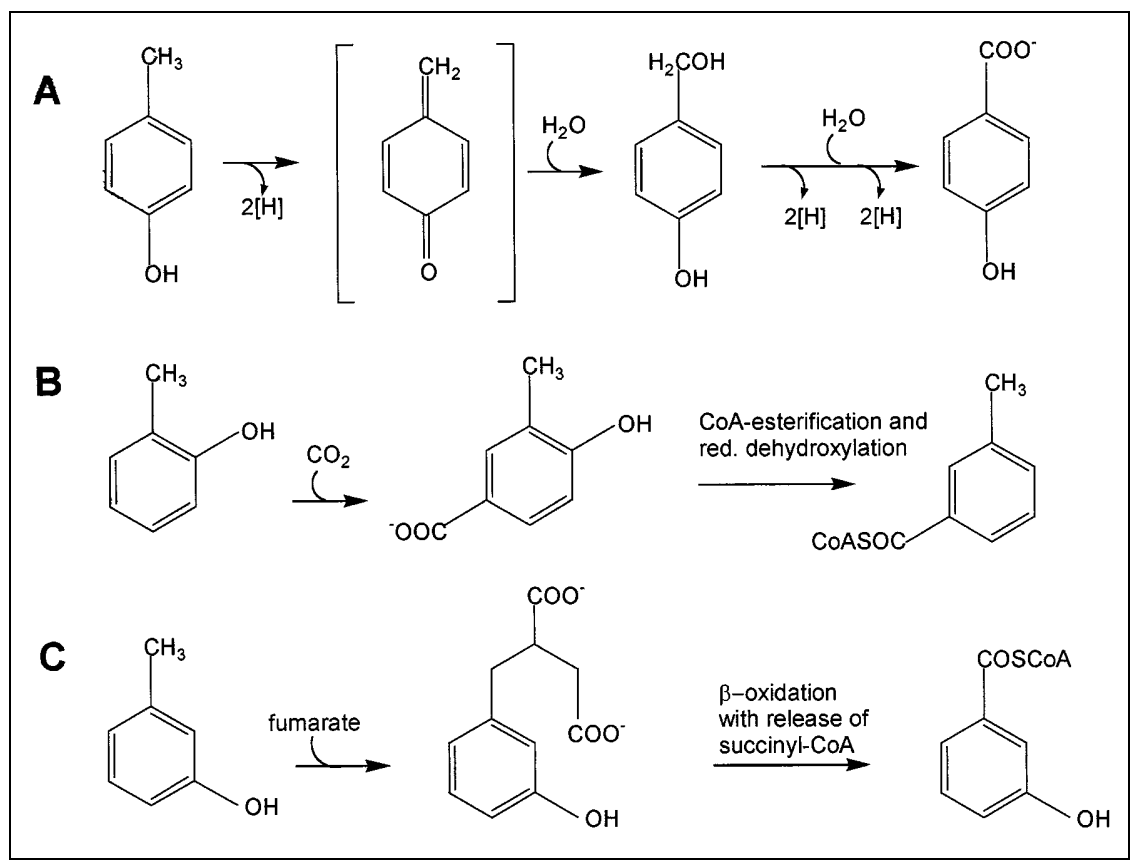

Fig. 3A-C. Initial steps in anaerobic degradation of cresols. A) Degradation of $p$-cresol. B) Degradation of $o$-cresol. C) Degradation of $m$-cresol thyl-4-hydroxybenzoate and further degraded as such (Fig. 3b; Bisaillon et al. 1991; Rudolphi et al. 1991). An alternative pathway could lead through methyl group hydroxylation, analogous to that in $p$ cresol, to form salicylic acid as an intermediate (Schink et al. 1992; Suflita et al. 1989), but experimental evidence of such a pathway is still lacking. Enrichment cultures with sulfate and $m$-cresol suggest carboxylation as primary activation reaction (Ramanand and Suflita 1991; Roberts et al. 1990), but it has not been confirmed that the 4-hydroxy2-methyl benzoic acid thus formed is really a degradation intermediate rather than a side product. The pathway of anaerobic $m$-cresol degradation has recently been elucidated with a pure culture of the sulfate-reducing bacterium Desulfobacterium cetonicum. This degradation follows a pathway analogous to anaerobic toluene degradation by nitrate-reducing bacteria (Müller et al. 1999): the methyl group of $m$-cresol adds to fumarate to form 3-hydroxybenzyl succinate. Activation and $\beta$-oxidation lead to succinyl-CoA and 3-hydroxybenzoyl-CoA (Fig. 3c). Thus the new type of methyl group addition to fumarate appears not to be restricted to the activation of aromatic hydrocarbons.

Aniline is degraded anaerobically through a pathway analogous to that of phenol degradation. The initial activation occurs by carboxylation to 4-aminobenzoate which is subsequently activated to 4-aminobenzoyl-CoA which undergoes reductive deamination to benzoyl-CoA (Schnell and Schink 1991).
The initial carboxylation reaction has not yet been studied in cell-free extracts, and nothing is known about an activated intermediate to provide the carboxylation reaction with the necessary energy. A primary phosphorylation as in the case of nitrate-dependent phenol degradation (see above) appears unlikely, but no reliable biochemical studies have as yet been performed on this system.

\section{Degradation of Divalent Phenols and Their Carboxylic Acids}

Hydroquinone is degraded by sulfate-reducing and fermenting bacteria. The degradation pathway has been studied with a Desulfococcus strain (Gorny and Schink 1994a) and a fermenting bacterium later described as Syntrophus gentianae (Gorny and Schink 1994b). In both cases hydroquinone is first carboxylated to gentisate; again, this carboxylation has not been studied in cell-free extracts, and the energetization of this reaction is unknown. Gentisate is activated to gentisyl-CoA through a CoA-ligase reaction. In $S$. gentianae gentisyl-CoA is reductively dehydroxylated to benzoyl-CoA, which enters the modified benzoyl-CoA pathway (Fig. 4a). The dehydroxylation of the two hydroxyl groups proceeds in a single step; no monohydroxylated intermediate has been detected or introduced into the reaction. The enzyme activity is membrane associated and 


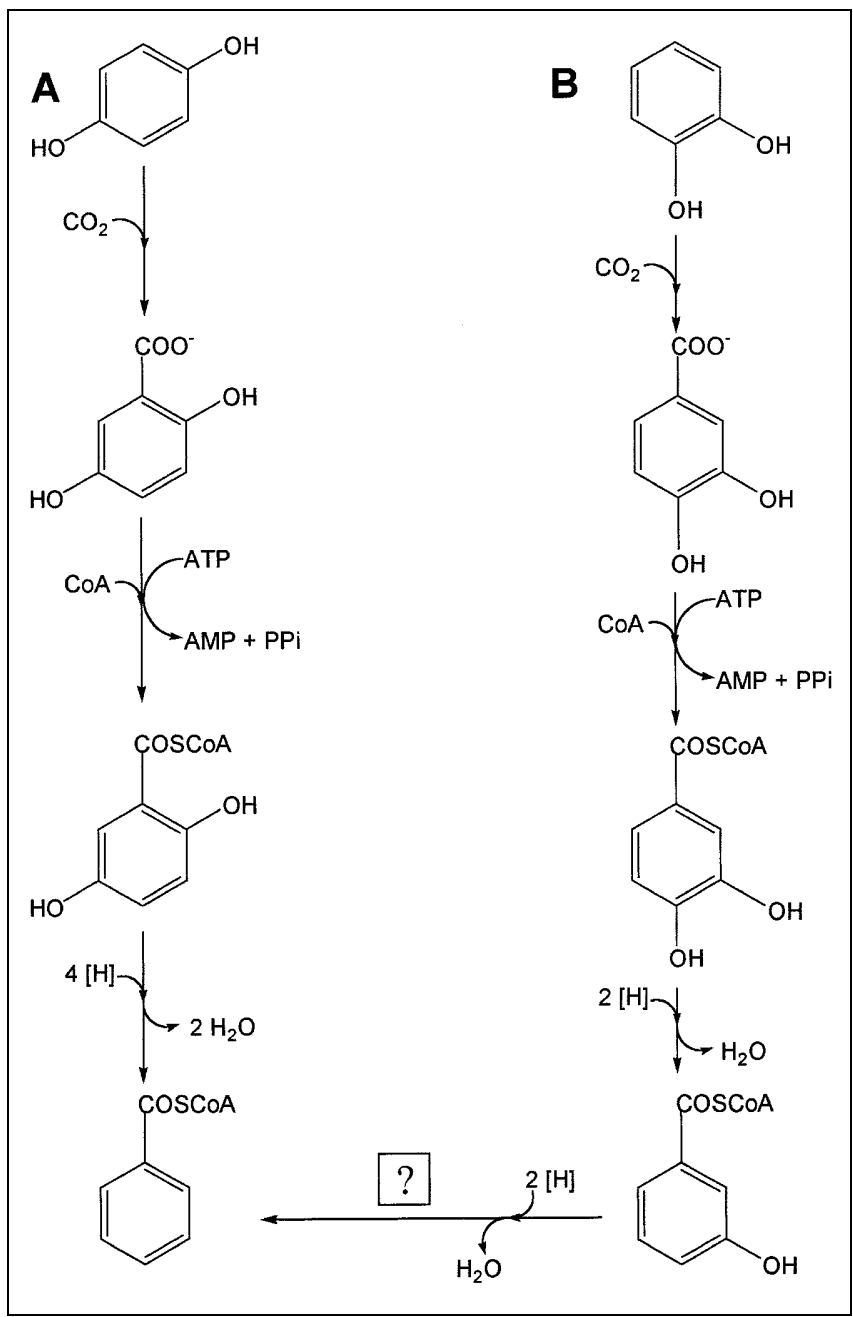

Fig. 4A,B. Initial steps in degradation of hydroquinone and catechol by sulfate-reducing and fermenting bacteria. The two pathways merge in the lower left at benzoyl-CoA. A) Degradation of hydroquinone. B) Degradation of catechol

may even help to conserve energy through a vectoral proton transport across the membrane. Gentisate is used by the fermenting bacterium accordingly and enters the described degradation pathway at a later stage. In the Desulfococcus strain gentisyl-CoA is not reduced to benzoyl-CoA but to some unknown products, perhaps due to a direct reduction of the benzene moiety.

Degradation of catechol, a key intermediate of aerobic breakdown of aromatic compounds, is by far the slowest of the divalent phenols under anoxic conditions. The biochemistry of catechol catabolism has been studied only with a sulfate-reducing Desulfobacterium strain, which carboxylates catechol to protocatechuate (Gorny and Schink 1994c). Protocatechuate is activated to form protocatechuyl-CoA which is subsequently dehydroxylated to benzoylCoA (Fig. 4b). In vitro only the hydroxyl group in $p$-position is removed, but indirect evidence argues for complete dehydroxylation to benzoyl-CoA. Efforts to isolate nitrate-reducing or fermenting bacteria with catechol as substrate have so far failed.

\section{Degradation of Resorcinol and Resorcylic Acids}

An entirely different strategy is taken in the anaerobic degradation of resorcinol and its carboxylated derivatives. The two hydroxyl groups in resorcinol are in positions to allow tautomerization to an unsaturated cyclohexenedione derivative with an isolated double bond (Fig. 5a). Cell-free extracts of a fermenting Clostridium strain convert resorcinol to dihydroresorcinol (Kluge et al. 1990; Tschech and Schink 1985) to form cyclohexanedione, which is further hydrolyzed to 5-oxohexanoate, probably by a nucleophilic attack on one of the carbonyl carbon atoms (Fig. 5a). The resorcinol reductase of this bacterium consists of subunits of $49.5 \mathrm{kDa}$ and contains flavin adenine dinucleotide, but iron sulfur centers have not been detected (Schüler 1997).

The resorcinol carboxylates $\beta$ - and $\gamma$-resorcylate are degraded by the same fermenting bacterium after decarboxylation to resorcinol. These decarboxylations are chemically easy because in these cases the carboxylic group is located in ortho- or para-position to hydroxyl groups.

No resorcinol-reducing activity can be identified in cultures of nitrate-reducing bacteria growing with resorcinol as sole substrate (Gorny et al. 1992; Kluge et al. 1990). An unsaturated 5-oxohexenoic acid was detected in culture supernatants of these bacteria, which led us to posit that these bacteria open the resorcinol ring by direct hydrolysis, without preceding reduction (Gorny et al. 1992). Only recently, however, we have found that resorcinol degradation by nitrate reducers uses an entirely different chemistry. Azoarcus anaerobius does not cleave the ring hydrolytically, but the resorcinol ring is destabilized by the introduction of a further hydroxyl group to form HHQ (Fig. 5b; Philipp and Schink 1998). The enzyme activity involved is membranebound, and the hydroxylation can be coupled to nitrate reduction to nitrite or to reduction of other electron acceptors with an $\mathrm{E}_{0}{ }^{\prime}$ higher than $+100 \mathrm{mV}$. The hydroxylase itself has not yet been isolated but is likely to be a molybdo enzyme, analogous to many other oxygen-independent hydroxylases (Hille et al. 1999). HHQ is oxidized to hydroxy- 


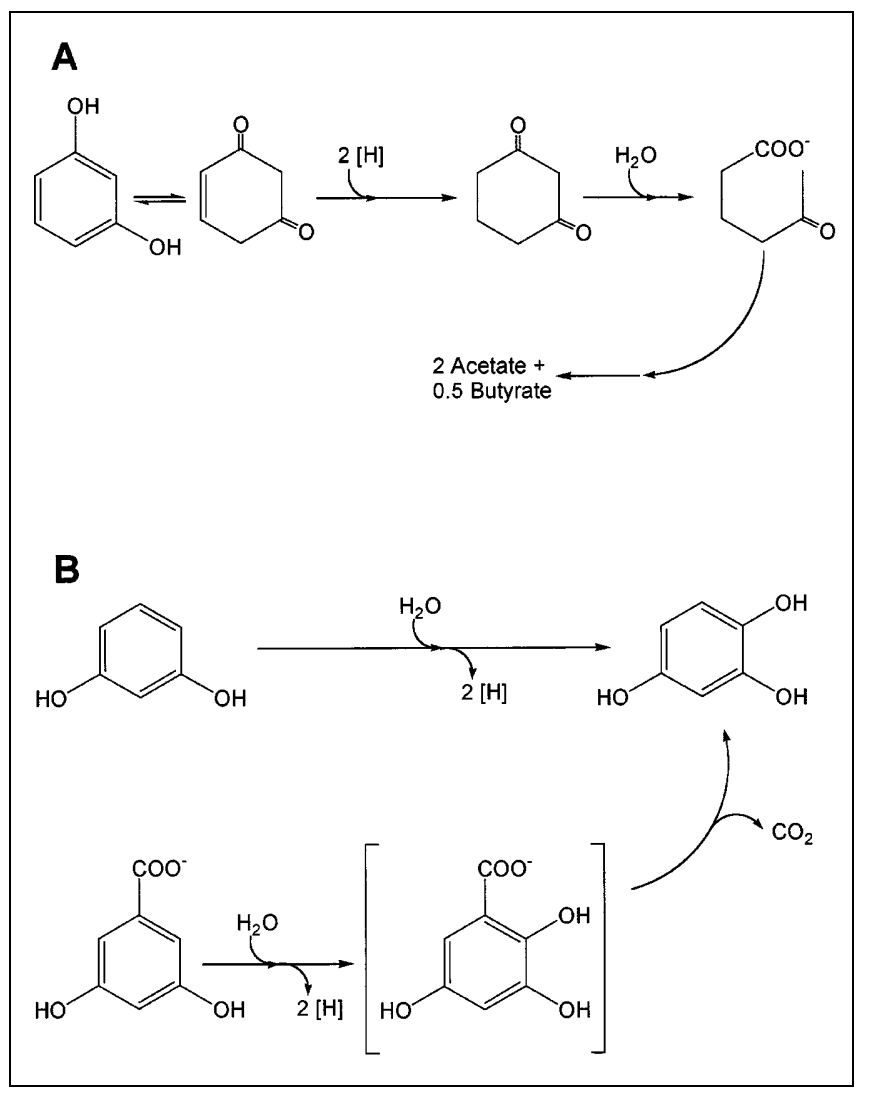

Fig. 5A,B. Initial steps in anaerobic degradation of resorcinol and $\alpha$ resorcylate. A) Resorcinol degradation by a fermenting bacterium, Clostridium strain KN245. B) Degradation of resorcinol and $\alpha$-resorcylate by nitrate-reducing bacteria

benzoquinone in a further oxidation step. This enzyme is also membrane bound (Philipp and Schink 1998). The further fate of hydroxybenzoquinone is still not entirely clear, but it should be prone to ring fission. In the presence of NADH plus nitrate, cellfree extracts of $A$. anaerobius convert hydroxybenzoquinone mainly to succinate and acetate and a number of other, yet unidentified products, indicating that the ring is cleaved to a two-carbon and a four-carbon moiety (Philipp and Schink, in preparation).

The new pathway of resorcinol degradation through hydroxylation to HHQ also opened a solution for anaerobic degradation of $\alpha$-resorcylate (3,5-dihydroxybenzoate). This compound is very stable and cannot be easily decarboxylated. The nitrate-reducing bacterium $T$. aromatica strain AR-hydroxylates $\alpha$-resorcylate to 3,5,6-trihydroxybenzoate, which is now easily decarboxylated to HHQ (Fig. 5b; Gallus and Schink 1998). The latter is further degraded through hydroxybenzoquinone. Thus this T. aromatica strain harbors, next to the benzoyl-CoA path- way, a second, mechanistically distinct pathway for degradation of certain aromatic compounds. The expression of both pathways appears to be strictly regulated (Philipp and Schink 1999).

The oxidation reaction of HHQ to hydroxybenzoquinone has a standard redox potential of $+180 \mathrm{mV}$ (Philipp and Schink 1998) which could explain why this strategy is followed only by nitrate-reducing bacteria and, as far as is known, not by sulfatereducing or fermenting bacteria.

\section{Degradation of Trihydroxybenzenes and Trihydroxybenzoates}

Among the three trihydroxybenzene isomers, pyrogallol and phloroglucinol are degraded quickly by fermenting bacteria and were the first aromatic compounds to be degraded by fermentation in pure culture (Schink and Pfennig 1982). Phloroglucinol degradation has been studied in detail with Eubacterium oxidoreducens and Pelobacter acidigallici. Phloroglucinol is reduced by an NADPH-dependent reductase to dihydrophloroglucinol (Fig. 6; Brune and Schink 1992; Haddock and Ferry 1989), and the same strategy is followed by Holophaga foetida strain TMBS4 (Kreft and Schink 1993). Hydrolytic ring cleavage leads to 3-hydroxy-5-oxohexanoic acid, which is thiolytically cleaved to three acetate residues (Brune and Schink 1992). This pathway is easy to conceive because the 1,3,5-arrangement of the three hydroxyl groups on the aromatic ring allows tautomerization to 1,3,5-trioxocyclohexane to a certain degree, which favors a reductive attack on the oxocarbon groups. The second trihydroxybenzene isomer, pyrogallol, cannot be hydrolyzed or reduced directly but is isomerized to phloroglucinol through a transhydroxylation reaction (Fig. 6; Brune and Schink 1990; Krumholz and Bryant 1988). The reaction requires 1,3,4,5-tetrahydroxybenzene as a cosubstrate, and the enzyme transfers a hydroxyl group from the tetrahydroxybenzene to pyrogallol, thus releasing phloroglucinol as product and the tetrahydroxybenzene as coproduct (Fig. 7; Brune and Schink 1990). The transhydroxylase enzyme has recently been characterized in detail. It contains an iron-sulfur center and a molybdopterin cofactor which probably acts as hydroxyl group carrier by a valency change in the molybdenum metal (Reichenbecher and Schink 1999; Reichenbecher et al. 1994, 1996).

The third trihydroxybenzene isomer, HHQ, is converted by the fermenting bacterium Pelobacter massiliensis to three acetate as well (Schnell et al. 1991), 


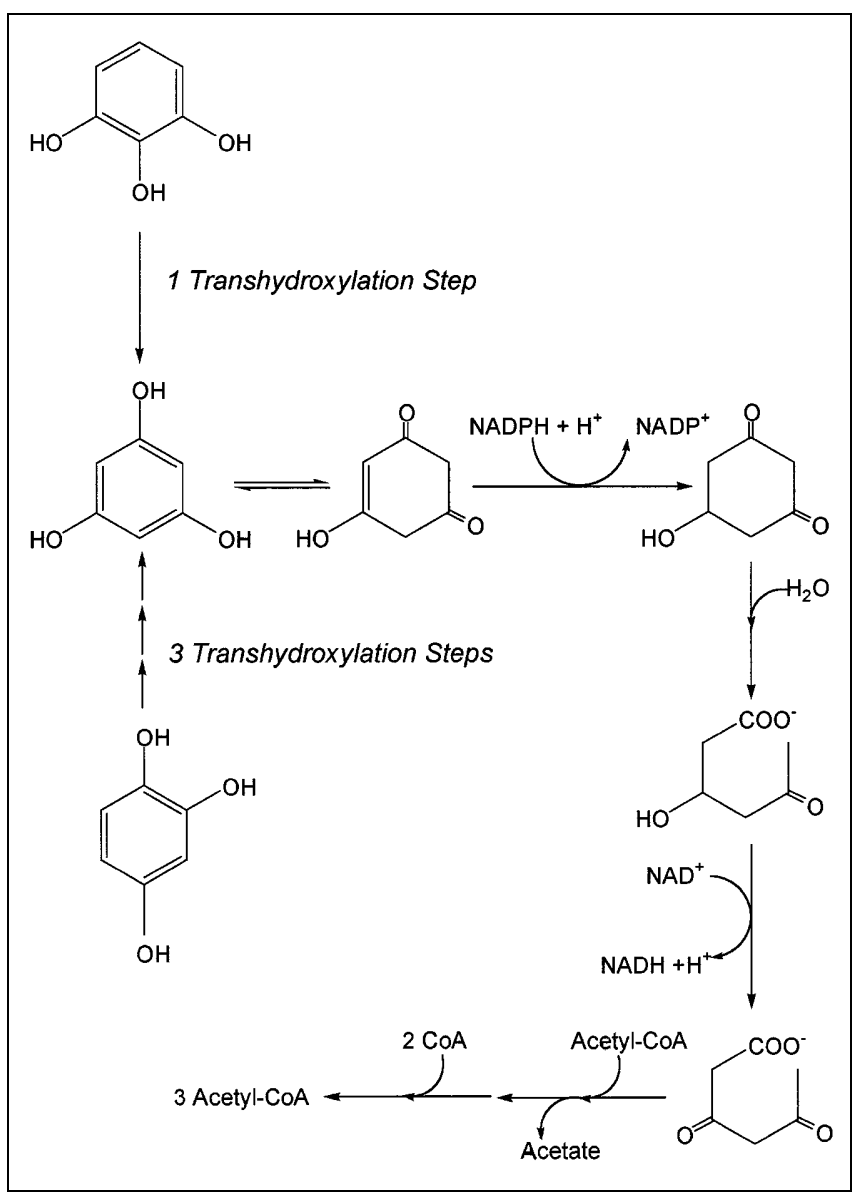

Fig. 6. Degradation of trihydroxybenzenes by fermenting bacteria

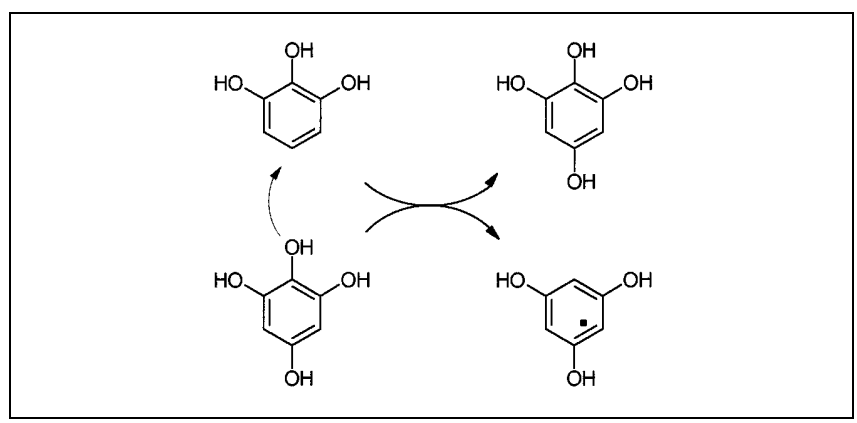

Fig. 7. Pyrogallol-phloroglucinol transhydroxylase reaction in Pelobacter acidigallici

indicating that this pathway also leads through phloroglucinol. The isomerization to phloroglucinol requires three subsequent transhydroxylation reactions analogous to the pyrogallol-phloroglucinol transhydroxylation, and indeed phloroglucinol is the final aromatic compound that is reduced and cleaved hydrolytically (Brune et al. 1992).
A<smiles>CC(C)C[Te]</smiles>

B

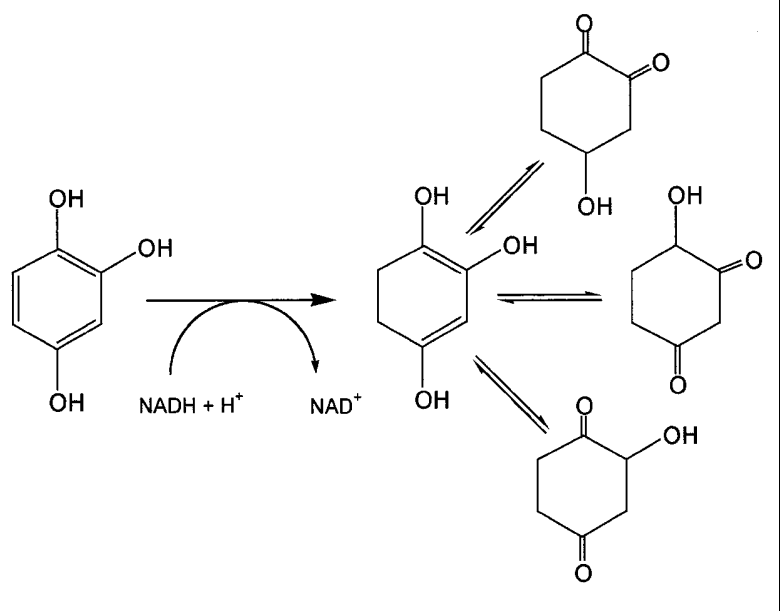

Fig. 8A,B. Initiation of anaerobic degradation of hydroxyhydroquinone. A) Oxidative destabilization by nitrate-reducing bacteria. B) Reductive destabilization by Desulfovibrio inopinatus

In addition to this strategy of isomerization to phloroglucinol which is taken by all fermenting bacteria, we recently found alternative pathways of HHQ degradation with nitrate-reducing and sulfate-reducing bacteria. HHQ degradation by nitrate-reducing bacteria was discussed above in the context of nitratedependent resorcinol degradation (Philipp and Schink 1998). The reaction leads, among others, to an acetate and a succinate residue, suggesting that the HHQ intermediate is cleaved between the carbon atoms 1 and 2 and 3 and 4 (Fig. 8a). The cleavage products found can easily be oxidized to $\mathrm{CO}_{2}$, with nitrate as electron acceptor. A further alternative of HHQ degradation was found with the sulfate-reducing bacterium Desulfovibrio inopinatus. This bacterium metabolizes HHQ according to the following equation: $\mathrm{C}_{6} \mathrm{H}_{6} \mathrm{O}_{3}+\mathrm{H}_{2} \mathrm{O}+\mathrm{SO}_{4}^{2-} \rightarrow$ $2 \mathrm{CH}_{3} \mathrm{COO}^{-}+2 \mathrm{CO}_{2}+\mathrm{HS}^{-}+\mathrm{H}^{+}$. In the first step HHQ is destabilized by reduction to dihydro-HHQ (Fig. 8b), and later acetate and an as yet unidentified 4-carbon derivative are formed (Reichenbecher et al. 1999). Since D. inopinatus is unable to oxidize acetate, the final products are two acetate and two $\mathrm{CO}_{2}$, and $1 \mathrm{~mol}$ sulfate is reduced concomitantly to 
sulfide. Thus the strategies of energy metabolism by the three different metabolic types of anaerobic bacteria are mirrored in their metabolic products: the fermenting bacterium produces as much acetate as possible and recovers a net amount of $2 \mathrm{ATP} / \mathrm{mol}$ HHQ via phosphotransacetylase and acetate kinase, following two thiolytic cleavage reactions. The sulfate-reducer which cannot oxidize acetate produces 2 acetate and uses the additional electrons for sulfate reduction to gain some additional energy through sulfate respiration. The nitrate reducer gains most of its energy in the oxidation of acetyl residues and forms only $\mathrm{CO}_{2}$ as terminal product.

Among the various trihydroxybenzoates, gallate appears to be the most important one, due its occurrences in, for example, oak gall and as degradation product of lignin or tannine. It is rapidly decarboxylated to pyrogallol by fermenting bacteria such as $E$. oxidoreducens and P. acidigallici (Brune and Schink 1992; Krumholz and Bryant 1988). Other trihydroxybenzoate isomers play a role also as intermediates in degradation of $\alpha$-resorcylate and probably gentisate. As for gallate, decarboxylation is easily achieved yielding HHQ in both cases.

\section{Conclusions}

The present survey shows that the degradation of aromatic compounds by anaerobic bacteria does not always follow a single strategy for every substrate. Comparison of fermenting, sulfate-reducing, and nitrate-reducing bacteria illustrates that numerous strategies are possible in the absence of oxygen for the breakdown of aromatic compounds, and the strategy taken appears to depend largely on the energy situation of the organism involved and the redox potentials of the electron acceptors that it can use. In the case of the benzoyl-CoA pathway there are indications that fermenting bacteria and sulfate reducers use a variant of the pathway originally described for nitrate reducers that requires less energy for benzoyl-CoA dearomatization. This appears plausible from the point of view that especially the fermenting bacteria have very little energy available.

An entirely new pathway was recently discovered, with HHQ as the central intermediate. Especially nitrate-reducing bacteria appear to use this pathway for substrate degradation, and several substrates such as resorcinol, $\alpha$-resorcylate, 3-hydroxybenzoate, gentisate, and perhaps hydroquinone are channeled towards HHQ by hydroxylations and decarboxylations (Fig. 9). The HHQ pathway thus

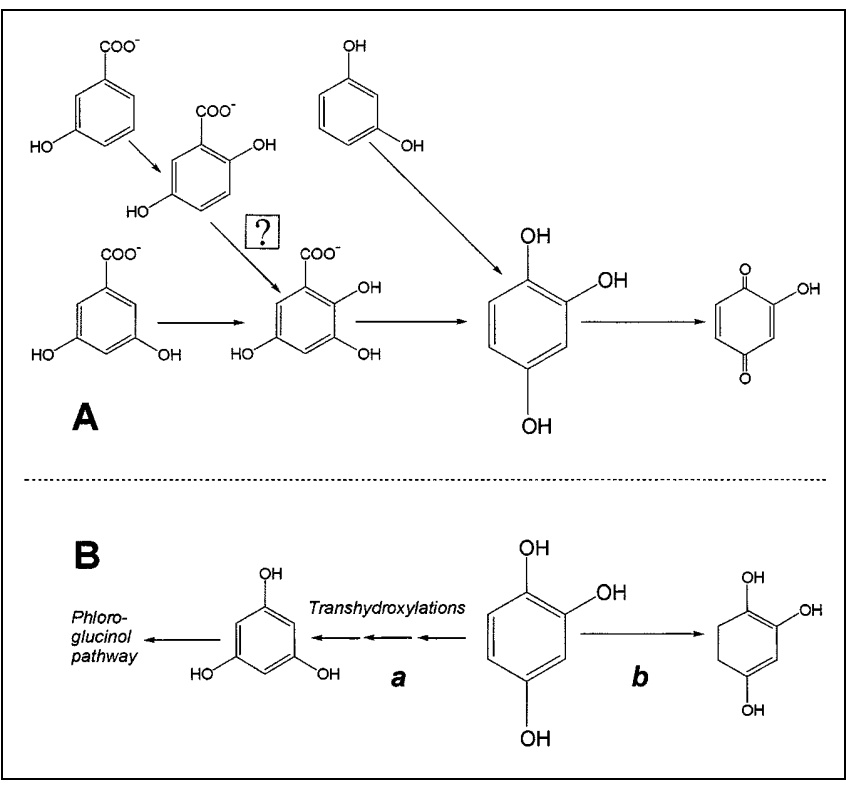

Fig. 9A,B. Hydroxyhydroquinone as a new intermediate in anaerobic degradation of various aromatic compounds

gains great importance in the transformation of phenolic compounds by nitrate-reducing bacteria, which prefer this pathway to the parallel pathways used by fermenting or sulfate-reducing bacteria.

The oxidative strategy by the recently discovered hydroxylations are clearly the preferred types of reactions used by nitrate-reducing bacteria which can easily dispose of the electrons released in these hydroxylation reactions. Sulfate-reducing and fermenting bacteria, on the other hand, avoid such steps and try to convert a substrate by isomerizations, carboxylations, and reductive modifications to intermediates that can be degraded without such difficult oxidation steps. No studies have yet been carried out on the pathways used for the degradation of aromatic compounds by iron reducers. The redox potential of their main electron acceptor $\left[\mathrm{Fe}\left(\mathrm{OH}_{3}\right) /\right.$ $\mathrm{Fe}^{2+}=+100 \mathrm{mV}$; Widdel et al. 1993] is between that used by the sulfate-reducers $\left(\mathrm{SO}_{4}^{2-} /\right.$ $\mathrm{HS}^{-}=-270 \mathrm{mV}$ ) and that of the first step in nitrate reduction $\left(\mathrm{NO}_{3}^{-} / \mathrm{NO}_{2}^{-},+430 \mathrm{mV}\right)$ and they may choose between the different pathways from case to case. Thus, beyond the mere availability of molecular oxygen, the redox potential of the electron-accepting system in anaerobic breakdown of aromatic compounds also determines the biochemical strategy that is applied for the breakdown of aromatic compounds. The biochemical diversity among anaerobic bacteria is therefore proving even greater than previously thought, as shown in this case by the pathways of anaerobic breakdown of aromatics. 
Acknowledgements. We thank the former students in this laboratory, Andreas Tschech, Andreas Brune, Sylvia Schnell, Norbert Gorny, Corinna Gallus, and Wolfram Reichenbecher for their dedicated work. We also appreciate the friendly and helpful cooperation with our colleagues Georg Fuchs, Wolfgang Buckel, and Friedrich Widdel. Work in the authors' laboratory was supported by grants from the Deutsche Forschungsgemeinschaft, the University of Constance, and the Fonds der Chemischen Industrie, Frankfurt am Main. Each of these is gratefully acknowledged.

Adler E (1977) Lignin chemistry - past, present, and future. Wood Sci Technol 11:169-218

Altenschmidt U, Fuchs G (1991) Anaerobic degradation of toluene in denitrifying Pseudomonas sp.: indication of toluene methylhydroxylation and benzoyl-CoA as central aromatic intermediate. Arch Microbiol 156:152-158

Ball HD, Johnson HA, Reinhard M, Spormann AM (1996) Initial reactions in anaerobic ethylbenzene oxidation by a denitrifying bacterium, strain EB1. J Bacteriol 178:5755-5761

Beller HR, Spormann AM (1997a) Anaerobic activation of toluene and o-xylene by addition to fumarate in denitrifying strain T. J Bacteriol 179:670-676

Beller HR, Spormann AM (1997b) Benzylsuccinate formation as a means of anaerobic toluene activation by sulfate-reducing strain PRTOL1. Appl Environ Microbiol 63:3729-3731

Beller HR, Spormann AM, Sharma PK, Cole JR, Reinhard M (1996) Isolation and characterisation of a novel toluene-degrading sulfatereducing bacterium. Appl Environ Microbiol 62:1188-1196

Biegert T, Altenschmidt U, Eckerskorn C, Fuchs G (1993) Enzymes if anaerobic metabolism of phenolic compounds. 4-HydroxybenzoateCoA ligase from a denitrifying Pseudomonas species. Eur J Biochem 213:555-561

Biegert T, Fuchs G, Heider J (1996) Evidence that oxidation of toluene in the denitrifying bacterium Thauera aromatica is initiated by formation of benzylsuccinate from toluene and fumarate. Eur J Biochem 238:661-668

Bissaillon JG, Lépine F, Beaudet R, Sylvestre M (1991) Carboxylation of $o$-cresol by an anaerobic consortium under methanogenic conditions. Appl Environ Microbiol 57:2131-2134

Boll M, Fuchs G (1995) Benzoyl-CoA reductase (dearomatizing), a key enzyme of anaerobic aromatic metabolism. ATP dependence of the reaction, purification and some properties of the enzyme from Thauera aromatica strain K172. Eur J Biochem 234:921-933

Boll M, Fuchs G (1998) Identification and characterisation of the natural electron donor ferredoxin and FAD as a possible prosthetic group of benzoyl-CoA reductase (dearomatizing), a key enzyme of anaerobic aromatic metabolism. Eur J Biochem 251:946-954

Boll M, Albracht SSP, Fuchs G (1997) Benzoyl-CoA reductase (dearomatizing), a key enzyme of anaerobic aromatic metabolism. A study of adenosintriphosphatase activity, ATP stoichiometry of the reaction and EPR properties of the enzyme. Eur J Biochem 244:840-851

Bonting CFC, Fuchs G (1996) Anaerobic metabolism of 2-hydroxybenzoic acid (salicylic acid) by a denitrifying bacterium. Arch Microbiol 165:402-408

Brackmann R, Fuchs G (1993) Enzymes of anaerobic metabolism of phenolic compounds. 4-Hydroxybenzoate-CoA reductase (dehydroxylating) from a denitrifying Pseudomonas species. Eur J Biochem 213:563-571

Brauman A, Müller JA, Garcia J-L, Brune A, Schink B (1998) Fermentative degradation of 3-hydroxybenzoate in pure culture by a novel strictly anaerobic bacterium, Sporotomaculum hydroxybenzoicum gen. nov. sp. nov. Int J Syst Bacteriol 48:215-221
Breese K, Fuchs G (1998) 4-hydroxybenzoyl-CoA reductase (dehydroxylating) from denitrifying bacterium Thauera aromatica. Prosthetic groups, electron donor, and genes of member of the molybdenum-flavin-iron-sulfur proteins. Eur J Biochem 251:916-923

Brune A, Schink B (1990) Pyrogallol-to-phloroglucinol conversion and other hydroxyl-transfer reactions catalyzed by cell extracts of Pelobacter acidigallici. J Bacteriol 172:1070-1076

Brune A, Schink B (1992) Phloroglucinol pathway in the strictly anaerobic Pelobacter acidigallici: fermentation of trihydroxybenzenes to acetate via triacetic acid. Arch Microbiol 157:417-424

Brune A, Schnell S, Schink B (1992) Sequential transhydroxylations converting hydroxyhydroquinone to phloroglucinol in the strictly anaerobic fermenting bacterium, Pelobacter massiliensis. Appl Environ Microbiol 58:1861-1868

Buckel W, Keese R (1995) Einelektronen-Redoxreaktionen von Coenzym-A-Estern in anaeroben Bakterien - ein Vorschlag für einen neuen Mechanismus. Angewandte Chem 107:1595-1598

Dagley S (1971) Catabolism of aromatic compounds by micro-organisms. Adv Microb Physiol 6:1-46

Dolfing J, Zeyer P, Binder-Eicher P, Schwarzenbach RP (1990) Isolation and characterisation of a bacterium that mineralises toluene in the absence of molecular oxygen. Arch Microbiol 154:336-341

El Kasmi A, Brackmann R, Fuchs G, Ragsdale S (1995) Hydroxybenzoyl-CoA reductase: coupling kinetics and electrochemistry to derive enzyme mechanisms. Biochemistry 34:11668-11677

Evans WC (1977) Biochemistry of the bacterial catabolism of aromatic compounds in anaerobic environments. Nature 270:17-22

Evans WC, Fuchs G (1988) Anaerobic degradation of aromatic compounds. Annu Rev Microbiol 42:289-317

Franck H-G, Stadelhofer JW (1987) Industrielle Aromatenchemie. Springer, Berlin Heidelberg New York

Fuchs G, El-Said Mohamed M, Altenschmidt U, Koch J, Lack A Brackmann R, Lochmeyer C, Oswald B (1994) Biochemistry of anaerobic biodegradation of aromatic compounds. In: Ratledge $\mathrm{C}$ (ed) Biochemistry of microbial degradation. Kluwer, Dordrecht, pp 513-553

Gallert C, Knoll G, Winter J (1991) Anaerobic carboxylation of phenol to benzoate: use of deuterated phenols revealed carboxylation exclusively in the $\mathrm{C} 4$ position. Appl Microbiol Biotechnol 36:124-129

Gallus C, Schink B (1998) Anaerobic degradation of a-resorcylate by Thauera aromatica strain AR-1 proceeds via oxidation and decarboxylation to hydroxyhydroquinone. Arch Microbiol 169:333-338

Galushko A, Minz D, Schink B, Widdel F (1999) Anaerobic degradation of naphthalene by a pure culture of a novel type of marine sulfate-reducing bacterium. Environ Microbiol 1:415-420

Gibson J, Dispensa M, Fogg GC, Evans DT, Harwood CS (1994) 4 Hydroxybenzoate-CoA S-ligase from Rhodopseudomonas palustris: purification, gene sequence, and role in anaerobic degradation. J Bacteriol 176:634-641

Gibson J, Dispensa M, Harwood CS (1997) 4-Hydroxybenzoyl-CoA reductase (dehydroxylating) is required for anaearobic degradation of 4-hydroxybenzoate by Rhodopseudomonas palustris and shares features with molybdenum-containing hydroxylases. J Bacteriol 179:634-642

Gorny N, Schink B (1994a) Complete anaerobic oxidation of hydroquinone by Desulfococcus sp. strain Hy5:indications of hydroquinone carboxylation to gentisate. Arch Microbiol 162:131-135

Gorny N, Schink B (1994b) Hydroquinone degradation via reductive dehydroxylation of gentisyl-CoA by a strictly anaerobic fermenting bacterium. Arch Microbiol 161:25-32

Gorny N, Schink B (1994c) Anaerobic degradation of catechol by Desulfobacterium $\mathrm{sp}$. strain Cat 2 proceeds via carboxylation to protocatechuate. Appl Environ Microbiol 60:3396-3340

Gorny N, Wahl G, Brune A, Schink B (1992) A strictly anaerobic nitrate-reducing bacterium growing with resorcinol and other aromatic compounds. Arch Microbiol 158:48-53 
Haddock JD, Ferry JG (1989) Purification and properties of phloroglucinol reductase from Eubacterium oxidoreducens G-41. J Biol Chem 264:4423-4427

Harms G, Zengler K, Rabus R, Aeckersberg F, Minz D, RossellóMora R, Widdel F (1999) Anaerobic oxidation of $o$-xylene, $m$-xylene, and homologous alkylbenzenes by new types of sulfate-reducing bacteria. Appl Environ Microbiol 65:999-1004

Harwood CS, Burchhardt G, Herrmann H, Fuchs G (1999) Anaerobic metabolism of aromatic compounds via the benzoyl-CoA pathway. FEMS Microbiol Rev 22:439-458

Healy JB Jr, Young LY (1978) Catechol and phenol degradation by a methanogenic population of bacteria. Appl Environ Microbiol $35: 216-218$

Healy JB Jr, Young LY (1979) Anaerobic biodegradation of eleven aromatic compounds to methane. Appl Environ Microbiol 38:84-89

Heider J, Fuchs G (1997) Anaerobic metabolism of aromatic compounds. Eur J Biochem 243:577-596

Heider J, Spormann AM, Beller HR, Widdel F (1999) Anaerobic bacterial metabolism of hydrocarbons. FEMS Microbiol Rev $22: 459-473$

Hille R, Rétey J, Bartlewski-Hof U, Reichenbecher W, Schink B (1999) Mechanistic aspects of molybdenum-containing enzymes. FEMS Microbiol Rev 22:489-501

Hopper DJ (1978) Incorporation of $\left[{ }^{18} \mathrm{O}\right]$ water in the formation of $p$-hydroxybenzyl alcohol by the p-cresol methylhydroxylase from Pseudomonas putida. Biochem J 175:345-347

Hopper DJ, Bossert ID, Rhodes-Roberts ME (1991) $p$-Cresol methylhydroxylase from a denitrifying bacterium involved in anaerobic degradation of p-cresol. J Bacteriol 173:1298-1301

Kluge C, Tschech A, Fuchs G (1990) Anaerobic metabolism of resorcylic acids ( $m$-dihydroxybenzoic acids) and resorcinol (1,3-benzenediol) in a fermenting and in a denitrifying bacterium. Arch Microbiol $155: 68-74$

Koch J, Eisenreich W, Bacher A, Fuchs G (1993) Products of enzymatic reduction of benzoyl-CoA, a key reaction in anaerobic aromatic metabolism. Eur J Biochem 211:649-661

Kreft J-U, Schink B (1993) Demethylation and further degradation of phenylmethylethers by the sulfide-methylating homoacetogenic bacterium strain TMBS4. Arch Microbiol 159:308-315

Krumholz R, Bryant MP (1988) Characterization of the pyrogallolphloroglucinol isomerase of Eubacterium oxidoreducens. J Bacteriol 170:2472-2479

Lack A, Fuchs G (1992) Carboxylation of phenylphosphate by phenol caboxylase, an enzyme system of anaerobic phenol metabolism in a denitrifying Pseudomonas sp. J Bacteriol 174:3629-3636

Lack A, Fuchs G (1994) Evidence that phenol phosphorylation to phenylphosphate is the first step in anaerobic phenol metabolism in a denitrifying Pseudomonas sp. Arch Microbiol 161:306-311

Lovley DR, Coates JD, Woodward JC, Phillips EJP (1995) Benzene oxidation coupled to sulfate reduction. Appl Environ Microbiol 61:953-958

Lovley DR, Woodward JC, Chapelle FH (1996) Rapid anaerobic benzene oxidation with a variety of chelated Fe (III) forms. Appl Environ Microbiol 62:288-291

Müller JA, Galushko AS, Kappler A, Schink B (1999) Anaerobic degradation of $m$-cresol by Desulfobacterium cetonicum is initiated by formation of 3-hydroxybenzylsuccinate. Arch Microbiol $172: 287-294$

Philipp B, Schink B (1998) Evidence of two oxidative reaction steps initiating anaerobic degradation of resorcinol (1,3-dihydroxybenzene) by the denitrifying bacterium Azoarcus anaerobius. J Bacteriol 180:3644-3649

Philipp B, Schink B (1999) Two different pathways for anaerobic degradation of aromatic compounds in the denitrifying bacterium Thauera aromatica strain AR-1. Arch Microbiol (in press)
Rabus R, Heider J (1998) Initial reactions of anaerobic metabolism of alkylbenzenes in denitrifying and sulfate-reducing bacteria. Arch Microbiol 170:337-384

Rabus R, Widdel F (1995) Anaerobic degradation of ethylbenzene and other aromatic hydrocarbons by new denitrifying bacteria. Arch Microbiol 163:96-103

Rabus R, Nordhaus R, Ludwig W, Widdel F (1993) Complete oxidation of toluene under strictly anaerobic conditions by a new sulfatereducing bacterium. Appl Environ Microbiol 59:1444-1451

Ramanand K, Suflita JM (1991) Anaerobic degradation of $m$-cresol in anoxic aquifer slurries: carboxylation reactions in a sulfate-reducing bacterial enrichment. Appl Environ Microbiol 57:1689-1695

Reichenbecher W, Schink B (1999) Towards the reaction mechanism of pyrogallol-phloroglucinol transhydroxylase of Pelobacter acidigallici. Biochim Biophys Acta 1430:245-253

Reichenbecher W, Brune A, Schink B (1994) Transhydroxylase of Pelobacter acidigallici: a molybdoenzyme catalyzing the conversion of pyrogallol to phloroglucinol. Biochim Biophys Acta 1204:217-224

Reichenbecher W, Rüdiger A, Kroneck PMH, Schink B (1996) One molecule of molybdopterin guanine dinucleotide is associated with each subunit of the heterodimeric Mo-Fe-S protein transhydroxylase of Pelobacter acidigallici as determined by SDS/PAGE and mass spectrometry. Eur J Biochem 237:406-413

Reichenbecher W, Philipp B, Suter M J-F, Schink B (1999) Hydroxyhydroquinone reductase, the first enzyme in hydroxyhydroquinone (1,2,4-trihydroxybenzene) degradation by Desulfovibrio inopinatus. Arch Microbiol (in press)

Roberts DJ, Fedorak PM, Hrudey SE (1990) $\mathrm{CO}_{2}$ incorporation and 4-hydroxy-2-methylbenzoic acid formation during anaerobic metabolism of $m$-cresol by a methanogenic consortium. Appl Environ Microbiol 56:472-478

Rudolphi A, Tschech A, Fuchs G (1991) Anaerobic degradation of cresols by denitrifying bacteria. Arch Microbiol 155:238-248

Schink B (1988) Principles and limits of anaerobic degradation - environmental and technological aspects. In: Zehnder AJB (ed) Biology of anaerobic microorganisms. Wiley, New York, pp 771-846

Schink B (1989) Mikrobielle Lebensgemeinschaften in Gewässersedimenten. Naturwissenschaften 76:364-372

Schink B, Pfennig N (1982) Fermentation of trihydroxybenzenes by Pelobacter acidigallici gen. nov. sp. nov., a new strictly anaerobic non-sporeforming bacterium. Arch Microbiol 133:195-201

Schink B, Brune A, Schnell S (1992) Anaerobic Degradation of Aromatic Compounds. In: Winkelmann G (ed) Microbial degradation of natural compounds. VCH, Weinheim, pp 219-242

Schlegel HG (1992) Allgemeine Mikrobiologie. Thieme, Stuttgart

Schnell S, Schink B (1991) Anaerobic aniline degradation via reductive deamination of 4-aminobenzoyl CoA in Desulfobacterium anilini. Arch Microbiol 155:183-190

Schnell S, Brune A, Schink B (1991) Degradation of hydroxyhydroquinone by the strictly anaerobic fermenting bacterium Pelobacter massiliensis sp. nov. Arch Microbiol 155:511-516

Schocher RJ, Seyfried B, Vazquez F, Zeyer J (1991) Anaerobic degradation of toluene by pure cultures of denitrifying bacteria. Arch Microbiol 157:7-12

Schöcke L, Schink B (1999) Biochemistry and energetics of fermentative benzoate degradation by Syntrophus gentianae. Arch Microbiol $171: 331-337$

Schüler KH (1997) Isolierung und mechanistische Untersuchung der Resorcin-Reduktase in Clostridium KN245. Thesis, University of Constance

Seyfried B, Glod G, Schocher R, Tschech A, Zeyer J (1994) Anaerobic degradation of toluene by pure cultures of denitrifying bacteria. Appl Environ Microbiol 60:4047-4052 
Suflita JM, Liang L-N, Saxena A (1989) The anaerobic degradation of $o-, m-$, and $p$-cresol by sulfate-reducing bacterial enrichment cultures obtained from a shallow anoxic aquifer. J Ind Microbiol $4: 255-266$

Tarvin D, Buswell AM (1934) The methane fermentation of organic acids and carbohydrates. J Am Chem Soc 56:1751-1755

Thauer RK, Jungermann K, Decker K (1977) Energy conservation in chemotrophic anaerobic bacteria. Bacteriol Rev 41:100-180

Tschech A, Fuchs G (1989) Anaerobic degradation of phenol via carboxylation to 4-hydroxybenzoate: in vitro study of isotope exchange between ${ }^{14} \mathrm{CO}_{2}$ and 4-hydroxybenzoate. Arch Microbiol $152: 594-599$
Tschech A, Schink B (1985) Fermentative degradation of resorcinol and resorcylic acids. Arch Microbiol 143:52-59

Tschech A, Schink B (1986) Fermentative degradation of monohydroxybenzoates by defined syntrophic cocultures. Arch Microbiol $145: 396-402$

Widdel F, Schnell S, Heising S, Ehrenreich A, Aßmus B, Schink B (1993) Anaerobic ferrous iron oxidation by anoxygenic phototrophs. Nature 362:834-836

Zhang X, Wiegel J (1994) Reversible conversion of 4-hydroxybenzoate and phenol by Clostridium hydroxybenzoicum. Appl Environ Microbiol 60:4182-4185 